\title{
Typologies of Preponderant Mindset among Single Parents of Children with ADHD
}

\section{Jocelyn B Hipona*}

Post Graduate Studies Program, Institute of Nursing, Far Eastern University, Sampaloc, Manila, Philippines

*Corresponding Author: Jocelyn B Hipona, Post Graduate Studies Program, Institute of Nursing, Far Eastern University, Sampaloc, Manila, Philippines. E-mail: jbhipona12@yahoo.com
Received: March 04, 2020

Published: April 29, 2020

(C) All rights are reserved by Jocelyn B

Hipona.

\begin{abstract}
Background and Objective: There are only few researches that tackle about the parenting style of single parents and their coping mechanism in response to their emotional stress in raising a child with ADHD. The purpose of this study is to explore the lived experiences, parenting style and coping mechanism of single parents in raising a child with ADHD. This study will provide an appropriate support from the healthcare providers to minimize their emotional stress and also to raise advocacy for single parents who are exceptional in caring for their child with this kind of disruptive behavior.

Methods: A qualitative research approach was utilized to describe lived experiences of single parents rearing children with ADHD and give them meaning.

This study utilized apurposive sampling and collected the data in primary schools in the Philippines, which offer special education and support for children with special conditions. A total of 4 single parents participated in this study that nurtures a clinically diagnosed ADHD child. A self-made 12 items questionnaires validated by experts was applied in this research to explore the experiences of single parents raising a child with ADHD, their strength and weakness and coping skills.

Results: Ideas were extracted through interview and the results revealed three different aspects in the care of these children. In cool and warm analyses, different factors show significant part in handling and caring for children. The study proved that being a single parent requires many functions and abilities. The result of this study captured the mindsets and perceptions of parents caring for children with ADHD.

Conclusion: Single parents who were involved in caring for their children that is clinically diagnosed with ADHD often have a positive outlook in their status and accepted the fact that their child is suffering from this disorder. They are also working hard to sustain the needs of their children. They were able to ascertain that a child with behavioral disorder does not make a difference in disciplining a normal child. It is essential to teach the parents to set firm limits and give consequences to their child's actions and not to be treated like a special child.

Keywords: Parenting Styles; Single Parents; Attention-Deficit-Hyperactivity-Disorder; Coping Mechanism
\end{abstract}

\section{Introduction}

According to Afolabi 0 [1] "Attention deficit hyperactivity disorder (ADHD) is a mental illness that can cause abnormal levels of hyperactivity and impulsiveness. People with ADHD may also have a hard time focusing their attention on a single task for short terms because they get distracted easily. Most people who don't have knowledge about this particular illness view the person as an annoying spoiled brat, but that is not the case. They can barely handle their impulse to do something, and if they do, they immediately skip to another activity. Due to their inability to concentrate and listen, educating them would be very difficult, and their parents must wield an unwavering patience and a very long temper if they want to teach them.
ADHD can interfere with their social learning. Children that has this kind of disorder are often hyperactive and distracted, which limits their ability to notice and imitate role models. They may also have trouble interacting with other kids and special education programs and sometimes they remove children with severe ADHD from traditional environments, which means that their peers, after whom they often model their behavior, end up being only other children with learning disabilities. ADHD can also interlope with self-efficacy, especially when a child believes or is told that he can't control his own behavior.

The decrease of observable symptoms of ADHD children can improve the family and socialization of the child with parenting behaviors in which it influences the child's behavior, schooling, and 
socialization with others [2]. According to Pfiffner L and Haack LJ [3] there are Behavior management treatments that usually use a non-pharmacological way to deal with ADHD children and other associated problems. Like Behavioral Parenting Training program that instructs the parents in doing positive consequences (e.g. giving praises, giving them rewards, etc.) to enrich parent-child or good family relationship. But there are also negative consequences when they disobey their parents or if they become aggressive or impulsive. The previous researchers have different treatment reviews about behavior management. Pelham and Fabiano (2008) assume that Behavior parenting training was a well-established treatment for children with ADHD.

According to the ADHD Society of the Philippines as of 2010 statistics report was $80 \%$ of adolescents manifest symptoms and $60 \%$ of adults as well. There are no specific etiologies identified for this disorder. Some researches assume that genetic component, particularly, Resistance to Thyroid Hormone (RTH) is related to the expression of ADHD, but it is only uncommon [4]. Some studies posited that Regions of Interest (ROI) is also responsible for the symptoms of ADHD, specifically, the area of the brain that has thinner cortical areas in their frontal lobes [5]. In several studies, environmental factors are identified as a factor contributing to the development of ADHD such as premature birth and fetal alcohol syndrome, and traumatic brain injury (TBI). This disorder is associated with mental health difficulties and social behavior that may lead to low self-esteem, very poor academic performance and serious behavioral problems [6]. It may result to long-term problems in adulthood such as underemployment, crime, and loss of productivity [7]. These problems may also have a negative impact on society and family functioning, particularly, to single parents who are raising a child with ADHD [8].

Peters K and Jackson D [8] discovered that single mothers who are raising a child with ADHD experienced being subjected to disapproval of the society, being scrutinized, and socially excluded. Parenting a child with an ADHD develops emotional stress among single parents and yet, they learn to be absolutely consistent and to be very, very nurturing to their child/children [9]. Since these children have greater demand on parenting, the parents just have to keep giving all their attention, all their love, and their reassurance [9]. There are only a few researches that tackle about the parenting style of single parents and their coping mechanism in response to their emotional stress in raising a child with ADHD. ADHD is not a result of poor parenting. Even though the parents are exceptional or terrible, they can still have a child that may exhibit symptoms of ADHD because there could be a genetic link.

\section{Purpose of the Study}

The purpose of this study is to explore the lived experiences, parenting style and coping mechanism of these single parents in raising a child with ADHD to provide an appropriate support that the researchers and healthcare providers/practitioners may give to minimize their emotional stress and also to raise advocacy for the single parents who are being exceptional in caring for their child with this kind of disruptive behavior. It will also encourage them to be involved in the parent training to demonstrate improvements in ADHD symptoms, to improve parental functioning, prevent severe behavioral, emotional and developmental problems, and enhance knowledge, skills and their confidence. Although the occurrence of ADHD cannot be prevented, good parenting will help their children to manage symptoms better.

\section{Method}

\section{Study design}

A qualitative research approach was utilized to describe lived experiences of single parents rearing children with ADHD and give them meaning. Phenomenological research is a design of inquiry coming from philosophy and psychology in which the researcher describes the lived experiences of individuals about raising children with ADHD as described by participants [10].

\section{Ethical procedures}

The ethical considerations of the study are anchored in the Nuremberg Code. The researcher provided the key informants with an informed consent giving them the right to agree or withhold their participation in the study. The investigator also have validated and evaluated the research for the good of society. The utilization of illicit journals has been made to provide enlightenment in order to support the study. The assurance of safety during interaction with the participants was observed. The results of the study raised awareness and provide support for single parents who are raising a child diagnosed with ADHD while keeping their confidentiality. The study established a connection with the principal in the school and then consulted the experiences of parents of a child diagnosed with ADHD. The key informants have the right to refuse or back out from participating in the study. The study will discontinue if the research will result to the harm and damage of reputation of the participants, of the university, and the researcher. The Institutional Ethics Review Committee (IERC) of a University located in Metro Manila, Philippines has reviewed the research proposal.

\section{Participants and sampling scheme}

The researcher has chosen a purposive sampling technique as the strategy for the sampling process. The sample selection has been based on the judgment of the researcher and the purpose of the research in the quest for people who have had experiences related to the phenomenon that is being researched. The researcher chooses 4 single parents who are raising a child diagnosed with ADHD and is enrolled in a special education school in Metro Manila, Philippines. The participants were asked a self- constructed questions that were validated by experts and their answers were recorded in an audiotape and cellphones. 


\section{Research instrument}

The study utilized 12 items of self-made questionnaires validated by experts to explore the experiences of a single parent raising a child diagnosed with ADHD, their strength and weakness and their coping skills.

\section{Data analysis}

The data collected was analyzed through a cool and warm analysis. The researcher extracted the significant statements of the interviewees and clustered the given information to form themes according to commonalities.

\section{Results and Discussion}

Through cool and warm analyses, the researcher came up with three (3) major themes describing the mindsets and perceptions of parents caring for children with ADHD, namely: (1) serve with regard to Caring For, (2) self as for Care Provider, and (3) subject concerning Care Recipient as shown in the Triadic Moving Gears representing the Three (3) Typologies of Preponderant Mindsets among Parents of Children with ADHD (Figure 1).

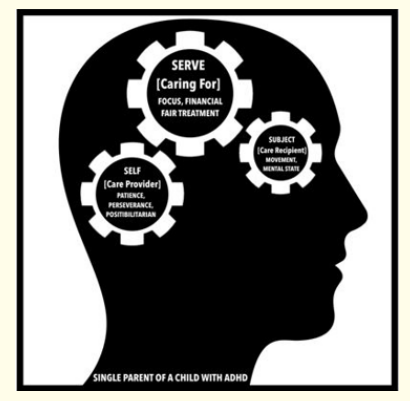

Figure 1: Triadic moving gears representing the three (3) typologies of preponderant mindset among parents of children with ADHD.

The "moving gears encased within the head figure" is the representation in this study. It stands for a clear thought or mindset and perception of a person, particularly, a single parent to deal with something in the matter of caring for a child with ADHD. "Serve" is the biggest gear among the two because as for the key informants, putting the interest of their child above their own is more important. Second is "self" as a parent they have to become to meet the demands of his/her child. The bottommost is the "subject" describing the child with an ADHD condition because this study focuses more on the understanding of a single parent caring for a child with ADHD than the child himself/herself.

\section{Theme 1: Serve}

Serving theme pertains to the roles of the caregiver. According to the data gathered by the researcher, the mother was focused on taking care of her child and provided full attention compared to permissive parents that don't tend to focus on teaching discipline to their child. They tend to be laid back and may only intervene where there is serious problem [11]. The other classified minor theme is fair treatment. Fair treatment is a treating a child like a normal one especially in disciplining them, they should be taught what behavior is expected from them, set from limits and consequences, and not to be treated like a special child, however, authoritative parent also have rules that children are expected to follow, however, they allow some exceptions to the rule. They often tell children the reasons for the rules and they are more willing to consider a child's feelings when setting limits. Authoritative parents tend to use consequences instead of punishments. They also use more positive consequences to reinforce good behaviors and may be more willing than authoritarian parents to use reward systems and praise [11].

\section{Theme 2: Self}

Self relates to the attributes of the caregiver. These attributes that the caregiver developed in caring for a child with ADHD are patience, perseverance and positibilitarian.

The participants developed patience as they are taking care of a child who is impulsive, inattentive and hyperactive. Patience is defined as the caregiver's ability to maintain composure while caring the child with ADHD.

Perseverance in caring for a child with ADHD started to unfold in order to continue striving through his/her hardships. In perseverance, a person can find solutions to even the toughest problems and remain strong. Being a parent for a child with an ADHD has no day-off; they still got to keep going.

Single parents got to initiate a possibilitarian attitude towards caring for a child with an atypical condition. Possibilitarian is defined as an optimism and acceptance in a situation. Some people work against acceptance and some work with it as if they had chosen it.

\section{Theme 3: Subject}

Subject concerning care recipient refers to the child with ADHD. Under this major theme, movement and mental state of a child with an ADHD is discussed.

The major theme "subject" embodies two minor themes, which is movement and mental state. According to Afolabi 0 [1] ADHD can interlude with their social learning. Children that have this kind of disorder are often hyper and distracted, which limits their ability to notice and imitate role models. They may also have trouble interacting with other kids and special education programs. On the contrary, it can be supported by the data gathered by the researcher where mother stated that in their house, he behaves well, but in school, he has a problem because there are children who were 
bullying him. And the other participant stated that her child is defiant, short-tempered, and hard to teach him. And when he wears his clothes, he cannot identify what is front and back. In the same way, according to Afolabi $O$ [1] the lower the observable symptoms of ADHD children can improve the family and socialization of the child with parenting behavior in which it influences the child's behavior, schooling, and socialization with others [11-58].

\section{Conclusion}

This research was conducted to encouraged single parents to get involved in the parenting education or seminars to improve parental functioning, to prevent severe behavioral, emotional and developmental problems, and to enhance their knowledge, skills, and confidence in caring a child with ADHD.

For healthcare providers such as nurses, this served as an avenue to raise awareness and help alleviate the emotional stress among single parents who were raising a child with ADHD.

Single parents who were involved in caring for their children that is clinically diagnosed with ADHD often have a positive outlook in their status and accepted the fact that their child is suffering from this disorder. They are also working hard to sustain the needs of their children. They were able to ascertain that a child with behavioral disorder does not make a difference in disciplining a normal child. It is essential to teach the parents to set firm limits and give consequences to their child's actions and not to be treated like a special child.

\section{Recommendation}

The difficulties of nurturing a child with ADHD can be physically and emotionally grueling. As a parent, the responsibility of setting the foundation of the child's emotional and physical health will start on how they were raised on many factors that can positively influence the symptoms of their disorder. It is vital to maintain a positive attitude, which is considered to be the parent's best asset for helping the child to meet the challenges of having ADHD. When a parent demonstrate calmness and attentiveness, it is more likely easier to have connection with the child and reinforcing them to be calm and focused too. Don't sweat the small stuff and be willing to make some compromises, a parent should create an atmosphere of impossible expectations for the child with ADHD. Compliment each tasks given to them and trust that the child can learn, change, mature and succeed.

\section{Bibliography}

1. Afolabi OE. "Attention-Deficit Hyperactivity Disorder (ADHD) in Children: A Move towards Developmental Perspectives". International Journal of School and Cognitive Psychology 3 (2016): 171.
2. Tarver J., et al. "Attention-deficit hyperactivity disorder (ADHD): an updated review of the essential facts". Child: Care, Health and Development 40.6 (2014): 762-774.

3. Pfiffner LJ and Haack LM. "Behavior Management for SchoolAged Children". Child and Adolescent Psychiatric Clinics of America 23.4 (2014): 731-746.

4. Nigg JT. "What causes ADHD?" Understanding what goes wrong and why. New York: Guilford Press (2006).

5. Almeida LG., et al. "Reduced right frontal cortical thickness in children, adolescents and adults with ADHD and its correlation to clinical variables: A cross-sectional study". Journal of Psychiatric Research 44 (2010): 1214 -1223.

6. Legg TJ. "ADHD by the Numbers: Facts, Statistics, and You". Healthline (2018).

7. Hunt Jason C. "Associations Between Different Parenting Styles and Child Behavior". PCOM Psychology Dissertations (2013): 262.

8. Peters K and Jackson D. "Mothers' experiences of parenting a child with attention deficit hyperactivity disorder". Journal of Advanced Nursing 65.1 (2008): 62-71.

9. Sullivan M. "Response to joint attention in toddlers at risk of autism spectrum disorder: a prospective study". Journal of Autism and Developmental Disorders 37.1 (2007): 37-48.

10. Creswell JW. "Qualitative Inquiry and Research Design: Choosing Among the Five Approaches". Thousand Oaks, CA: SAGE Publications, Inc (2013): 77-83.

11. Morin A. "4 Types of Parenting Styles: Learn How Each Parenting Style Affects Children". Whitney Institute Middle School (2016)

12. Adimora D., et al. "Parenting Styles and Attention Deficit Hyperactivity Disorder as Correlates of Academic Adjustment of In-School Adolescents in Enugu State, Nigeria". Procedia - Social and Behavioral Sciences 205 (2015): 702-708.

13. Aghebati A., et al. "Triple P-Positive Parenting Program for Mothers of ADHD Children". Iranian Journal of Psychiatry and Behavioral Sciences 8.1 (2014): 59-65.

14. Alizadeh $\mathrm{H}$ and Andries C. "Interaction of Parenting Styles and AttentionDeficit Hyperactivity Disorder in Iranian Parents". Child and Family Behavior Therapy 24.3 (2002): 37-52.

15. Altiere MJ and Von Kluge S. "Family functioning and coping behaviors in parents of children with autism". Journal of Child and Family Studies 18 (2009): 83-92. 
16. Benzies $\mathrm{K}$ and Mychasink R. "Fostering family resiliency: a review of the key protective factors". Child and Family Social Work 14.1 (2009): 103-114.

17. Brooks J. Process of Parenting 9th edition. McGraw-Hill Education (2012)

18. Brown TE., et al. "Executive function impairments in high IQ children and adolescents with ADHD". Open Journal of Psychiatry 1 (2011): 56-65.

19. Cabbeh KD., et al. "Lived Experiences of Parents of Children with Intellectual Disability Undergoing Pre-Vocational Education". Proceedings of the DLSU Research Congress (2015): 3.

20. Chacko A., et al. "Enhancing traditional behavioral parent training for single mothers of children with ADHD". Journal of Clinical Child and Adolescent Psychology 38 (2009): 206-218.

21. Chiu M. "Being a single dad can shorten your life". Manila Bulletin (2018).

22. Curwen J. "The Resiliency Theory: Caregiver Hope in Adversity. Positive Psychology Program (2016).

23. Deault L. "A Systematic Review of Parenting in Relation to the Development of Comorbidities and Functional Impairments in Children with Attention Deficit/Hyperactivity Disorder (ADHD)". Child Psychiatry and Human Development 41.2 (2010): 168-192.

24. Dowd NE. "In Defense of Single-Parent Families". New York University Press 2.2 (1997).

25. Ellis B and Nigg J. "Parenting practices and attention-deficit/ hyperactivity disorder: new findings suggest partial specificity of effects". Journal of the American Academy of Child and Adolescent Psychiatry 48.2 (2009): 146-154.

26. Evans S., et. al. "Evidence-Based Psychosocial Treatments for Children and Adolescentswith Attention-Deficit/Hyperactivity Disorder". Journal of Clinical Child and Adolescent Psychology: The Official Journal For the Society of Clinical Child and Adolescent Psychology, American Psychological Association, Division 43.4 (2014): 527-551.

27. Fabiano GA., et al. "A meta-analysis of behavioral treatments for attention-deficit/hyperactivity disorder". Clinical Psychology Review 29 (2009): 129-140.

28. Flewelling J. How does ADHD in Children Impact Academic Performance? Beyond Book Smart.

29. Golombok S., et al. "Single Mothers by Choice: Mother-Child Relationships and Children's Psychological Adjustment". Journal of Family Psychology 30.4 (2016): 409-418.
30. Gallopeni F. "Parenting Styles: Interaction with Hyperactivity”. European Journal of Social Sciences 10.2 (2017): 149-152.

31. Gray DE. 'Everybody just freezes. Everybody is just embarrassed': Felt and enacted stigma among parents with high functioning autism". Sociology of Health and Illness 24 (2002): 734-749.

32. Green SE. "What do you mean 'what's wrong with her?'”: stigma and the lives of families of children with disabilities". Social Science and Medicine 57 (2003): 1361-1374.

33. Guest G., et al. "How many interviews are enough? An experiment withdata saturation and variability". Field Methods 18.1 (2006): 24

34. Hook JL and Chalasani S. "Gendered expectations? Reconsidering single fathers' child-care time". Journal of Marriage and Family 70 (2008): 978-990.

35. Ishak Z., et al. "Parenting Style as a Moderator for Students' Academic Achievement". Journal of Science Educational Technology 21 (2012): 487-493.

36. Linares JL., et. al "Family Functioning and Parental Bonding During Childhood in Adults Diagnosed With ADHD". Journal of Attention Disorders (2015).

37. Lindsey H. "Relations between Parenting Stress, Parenting Style, and Child Executive Functioning for Children with ADHD or Autism". Journal of Child and Family Studies 25.12 (2016): 3644-3656.

38. Marsh D., et al. "The family experience of mental illness: Evidence for resilience". Psychiatric Rehabilitation Journal 20.2 (1996): 3-12.

39. Mc Cubbin MA. "Family stress theory and the development of nursing knowledge about family adaptation". In S.L. Feetham, S.B. Meister, J.M.Bell, and C.L. Gillis (Eds.) The Nursing Family. New Bury Park: Sage Publications (1993): 46-58.

40. McCubbin MA and McCubbin HI. "Families coping with illness: The resiliency model of family stress, adjustment and adaptation". In, C.B. Danielson, B. Hamel-Bissel, and P.Winstead-Fry, Families, health and illness: Perspectives on coping and intervention. St. Louis: Mosby (1989).

41. McGrath PJ., et al. "Telephone-based mental health interventions for child disruptive behavior or anxiety disorders: Randomized trials and overall analysis". Journal of the American Academy of Child and Adolescent Psychiatry 50 (2011): 11621172. 
42. Molina MF and Musich FM. "Perception of Parenting Style by Children with ADHD and Its Relation with Inattention, Hyperactivity/Impulsivity and Externalizing Symptoms". Journal of Child and Family Studies, 25.5 (2016): 1656-1671.

43. Molina MF. "Perceived Parenting Style and Self-Perception in Children with Attention Deficit/Hyperactivity Disorder". International Journal of Psychological Research 8.1 (2015): 61-64.

44. Motamedi B. Attention deficit hyperactivity disorder. Health day news for healthier living (2016).

45. Patterson J. "Family resilience to the challenge of a child's disability". Pediatric Annals 20.9 (1999): 491-499.

46. Predescu E and Sipos R. "Cognitive Coping Strategies, emotional distress and quality of life in mothers of children with ASD and ADHD - A Comparative Study in a Romanian population sample". Open Journal of Psychiatry 3.2A (2013): 11-17.

47. Quilin RL. "L-methylfolate treatment for psychiatric or neurologic disorders". U.S. Patent Documents, US 8,389535 B2 (2012).

48. Sanders C. "Application of Colaizzi's method: Interpretation of an auditable decision trail by a novice researcher". Contemporary Nurse Journal 14.3 (2003): 292- 302.

49. Shosha GA. "Employment of Colaizzi's Strategy in Descriptive Phenomenology: A Reflection of A Researcher". European Scientific Journal 8.27 (2007): 31-43.

50. Silva A and Urbano R. "Child ADHD Severity, Behavior Problems and Parenting Styles". Annals of Psychiatry and Mental Health 4.3 (2016): 1066.

51. Sobralske MC. "Perceptions of health: Navajo Indians". Topics in Clinical Nursing, 7.3 (1985): 32-39.

52. Speziale HJ and Carpenter DR. "Qualitative Research in Nursing: Advancing the Humanistic Imperative, ( $4^{\text {th }}$ edition.)". Philadelphia. Lippincott, Williams and Wilkins (2007).

53. Stuart M and McGrew JH. "Caregiver Burden after Receiving A Diagnosis of an Autism Spectrum Disorder". Research in Autism Spectrum Disorders 3.1 (2009): 86-97.

54. Teixeira MC., et al. "Associations between Inadequate Parenting Practices and Behavioral Problems in Children and Adolescents with Attention Deficit Hyperactivity Disorder". The Scientific World Journal (2015).

55. Young J. "Study Shows That ADHD Treatment Improves Parenting". Psychology Today (2009).
56. Yousefia S., et al. "Parenting stress and parenting styles in mothers of ADHD with mothers of normal children". Procedia - Social and Behavioral Sciences 30 (2011): 1666-1671.

57. Yates T., et al. "Resilience Theory and the Practice of Positive Psychology from Individuals to Societies". Public Policy and Systems for Resilience and Social Planning (2014): 773-784.

58. Zauszniewski JA., et al. "Resilience in Family Members of Persons with Serious Mental Illness". Nursing Clinics of North America 45.4 (2010): 613-626.

\section{Assets from publication with us}

- Prompt Acknowledgement after receiving the article

- Thorough Double blinded peer review

- Rapid Publication

- Issue of Publication Certificate

- High visibility of your Published work

Website: www.actascientific.com/

Submit Article: www.actascientific.com/submission.php Email us: editor@actascientific.com

Contact us: +919182824667 